\title{
What happens if you single out? An experiment
}

\author{
Fabio Galeotti · Daniel John Zizzo
}

Received: 30 December 2013 / Accepted: 22 January 2014 / Published online: 18 February 2014

(C) The Author(s) 2014. This article is published with open access at Springerlink.com

\begin{abstract}
We present an experiment investigating the effects of singling out an individual on trust and trustworthiness. We find that (a) trustworthiness falls if there is a singled out subject; (b) non-singled out subjects discriminate against the singled out subject when they are not responsible of the distinct status of this person; (c) under a negative frame, the singled out subject returns significantly less; (d) under a positive frame, the singled out subject behaves bimodally, either selecting very low or very high return rates. Overall, singling out induces a negligible effect on trust but is potentially disruptive for trustworthiness.
\end{abstract}

\section{Introduction}

We present the results of an experiment to test the effect of singling out an individual on trust and trustworthiness. The act of singling out an individual from a group based on his or her socio-economic categories (e.g. gender, race, age, income, political view) is a pervasive phenomenon of economic and social life. It occurs whenever a subject, who has specific attributes that make him or her potentially different from the others, ceases to be an ordinary and usual person, and becomes a distinct one in the eyes of the other people. More precisely, singling out can be defined as an inter-group situation in which one group is a singleton group made up of a single individual- the singled out individual-, whose social identity is perceived as different by a second group that is larger in size.

Electronic supplementary material The online version of this article (doi:10.1007/s00355-014-0795-x) contains supplementary material, which is available to authorized users.

F. Galeotti · D. J. Zizzo ( $\square)$

CBESS and School of Economics, University of East Anglia, Norwich, NR4 7TJ, UK

e-mail:d.zizzo@uea.ac.uk 
Someone can be singled out because he or she possesses some desirable qualities; therefore, the status of being singled out can be associated with a positive social standing. For instance, in organizational and workplace settings, an employee may be object of social recognition or appraisal for his or her desirable socio-economic characteristics (e.g. age or experience) or because he or she belongs to a privileged group, such as in the case, reported by Heikes (1991), of white-male nurses working in all-female environment. As result, he or she loses the status of ordinary member, and acquires a positive aura of uniqueness in the eyes of his or her colleagues or superiors. A subject can also be singled out by others because he or she possesses undesirable qualities; therefore, the status of being singled out can coincide with a negative social standing. In line with the previous example, an employee may be singled out by his or her colleagues or a superior for reproach or because he or she is disliked within the team or belongs to socially disadvantaged minorities, such as women or racial/ethnic minorities. The literature in social psychology offers several examples of solo or token individuals who have been singled out in the workplace by colleagues or superiors because of their undesirable qualities (e.g. see Kanter 1977; Yoder and Aniakudo 1997; Niemann and Dovidio 1998; DePaulo and Morris 2006). When the status of being singled out is attributable to something undesirable about the socio-economic characteristics of the subject, the latter may also be object of social exclusion, marginalization, stigmatization, negative stereotypes, bullying, or, more generally, negative discrimination (e.g. Heatherton et al. 2000; Abrams et al. 2005). In other words, the status of being singled out can be a precondition for these social mechanisms.

While in some cases there may be a consensus among the members of the group on who is the singled out individual, in others the latter is selected by a specific individual, such a manager in an organizational setting: ${ }^{1}$ an agent who has the right and power to enforce the status of being singled out.

This paper presents an experiment designed to test specifically the behavioral implications of singling out. We do so in the context of trust games. A trust game is a standard stylized setup used in the economic literature to study trusting behavior and trustworthiness. Economists are aware of the importance that both trust and trustworthiness play in economic interactions, especially with respect to the formation of social capital (e.g., Putnam 2000). In particular, they reduce the costs of transacting (Frank 1988), promote efficiency in markets (Arrow 1974), improve cooperation (Smith et al. 1995) and increase firms' ability to adapt to complexity and change (Korsgaard et al. 1995). Trust and trustworthiness are also considered to be "at the core of group life" (Hogg et al. 2005, p. 193). In particular, they play a fundamental role in ensuring the stability of a group or a team, and, therefore, are important in organizational and workplace settings. Anything that perturbs the stability of the group or team may affect the way in which the members trust and fulfill each other's trust. As singling out may have

\footnotetext{
1 Other examples are a teacher in a classroom or a superior in an army force (for instance, think of the overweight, and bumbling marine soldier who was named 'gomer pyle' by the drill instructor, in the Kubrick's movie Full Metal Jacket).
} 
important consequences in terms of group and team cohesion in organizations, it may then also affect trust and trustworthiness. For this reason, the trust game appears to be a natural environment where to test, as a starting point, the economic implications of singling a member out in a group.

To test these implications, we artificially induced a status of being singled out in the lab. Under a positive frame, the most preferred match in the experiment is singled out, whereas, under a negative frame, the least preferred match in the experiment is singled out. We controlled for identification effects by varying the extent to which the status of being singled out could be identified by non-singled out subjects. That is, in certain sessions, the singled out individual was identified with a mark (i.e. an asterisk), and, therefore, recognizable by the other subjects, whereas in other sessions the singled out participant was not marked with an asterisk, and, therefore, could not be identified by the other participants. Furthermore, we tested the implications of having a random assignation of such status under a neutral frame. In particular, rather than having the status of being singled out assigned by the participants, it is randomly assigned by the computer and, therefore, is not associated to being the least or most preferred match. We also investigated the effects of singling a member out under a negative frame when one specific individual rather than the whole group is responsible of such decision. To check the robustness of our results against what we refer as the individual characteristics hypothesis, we tested and rejected the possibility that singled out subjects behaved differently because of the individual characteristics that made them singled out. As such, this study provides evidence of the 'pure' effect of singling out an individual from a group, controlling for the individual characteristics of the singled out individual.

Our key finding is that singling out individuals has a negligible effect on trust and is potentially negative in terms of trustworthiness. More specifically, we find that singled out subjects in the negative framework return considerably less than non-singled out subjects, probably because they do not feel any bond with the other members but anger and resentment for the attribution of a lower status. In contrast, the singled out subjects in the positive framework display a bimodal behavior, returning either more or less, probably depending on whether they perceives themselves as insiders or outsiders. We also find that non-singled out subjects return substantially less to the singled out subject but only when they do not feel responsible of the distinct status of this person. Finally, we find that trustworthiness generally decreases if there is a singled out subject. Section 2 briefly reviews some of the related literature. Section 3 describes the experimental design. Section 4 presents the alternative behavioral conjectures about the implications of singling an individual out. Section 5 reports the main results. Section 6 provides a discussion of the findings and concludes.

\section{Related literature}

In the economic literature, we did not locate any papers that specifically analyze the economic implications of singling an individual out based on socio-economic cate- 
gories. ${ }^{2}$ However, an area of economic research somewhat related to our study is the one that examines experimentally the impact of group identity. In our experiment, we manipulate the social identity and status of one member, the singled out subject (and, therefore, indirectly that of the other members, the non-singled out subjects), within the reference group, thus creating de facto two potential distinct units: a majority group and a singleton group, i.e. a group represented by only one individual. Hence, our manipulation may have implications in line with the main findings of the economic literature on group identity. Although there are several experimental works that looked at group identity in economics (e.g. Hargreaves-Heap and Varoufakis 2002; Tan and Bolle 2007; Chen and Li 2009; Hargreaves-Heap and Zizzo 2009; Chen and Chen 2011), none of them has considered a case of social fragmentation like the one implemented in our experiment, in the context of a trust game. Two recent papers of this literature are however particularly relevant for our study. The first is Tsutsui and Zizzo (forthcoming). In this study, the authors investigated the role played by majority versus minority groups, and high status versus low status groups in the context of trust games. ${ }^{3}$ They observed that minority and low status subjects dislike being in such condition, and discriminate generally less. The second study is Chakravarty and Fonseca (2012), who studied the effects of social fragmentation and group identity on public good contributions. While their vehicle of research (i.e. a six-player public good game) differs from the one used in our experiment (i.e. a two-player trust game), in one treatment they induce a social fragmentation resembling that of our experiment (i.e. one subject experiencing solo status). They found that minority group subjects contribute more to the public good than majority group and middle-sized group subjects. ${ }^{4}$

Another stream of research that is to some extent related to our study is the one that looks at status, social recognition and ranking as a form of incentive in organizations (e.g. Eriksson et al. 2012; Neckermann et al. 2012; Charness et al. 2013). This type of mechanisms might evolve in or conceal a 'singling out' phenomenon insofar as the allocation of the immaterial award or the implementation of the ranking is not based solely on performance but it is, for example, based on subjective evaluation (see, for instance, Neckermann et al. 2012) or the awarded individual starts to be perceived differently by the others. All these studies have only considered the impact of such

\footnotetext{
2 There is a recent and interesting literature, in particular on public good games, that looked at how "conferring status" to one or few members of the group affects plays of the game. However, none of these studies considered the implications of a subject being disliked or liked, hence singled out by the others, within a group. In particular, in that literature, status is usually conferred to subjects who obtained the highest/lowest score in unrelated quizzes, and implies additional changes on how, for example, information is transmitted to the players (e.g. Eckel et al. 2010); or it is conferred at the end of a play to top contributors as a form of incentive to stimulate competition and promote cooperation (e.g. Pan and Houser 2011). Other early studies explored more broadly the implications of social status, for instance, in markets (e.g. Ball et al. 2001), and bargaining games (e.g. Ball and Eckel 1998). However, differently to our study and the literature described above, status was not conferred to only one individual but to groups of subjects.

3 The group size varied from 4 subjects (minority) to 8 subjects (majority). Group status was manipulated by labeling the high status group in terms of Blue group, whereas the low status group in terms of subjects who do not belong to any group (Tsutsui and Zizzo, forthcoming).

4 These results might be affected by reputational effects. In particular, largely in treatment 5-1, and weakly in treatment 4-2, minority group individuals are easily detectable even if the software randomized the display order of the individual contributions.
} 
managerial tools on performance, without looking at their potential side effects (in terms of inducing 'singling out') on trust and trustworthiness in the workplace. On similar grounds, singling out may be also related to leadership, insofar as the leader acquires uniqueness in the eyes of the others. Most of the economic literature on leadership focused on the implications of having a leader making a public decision (e.g. contribution to a public good) or sending a public message before the decisions of the other players (e.g. Güth et al. 2007; Potters et al. 2007; Gächter et al. 2012). Some of these studies also compared different mechanisms of appointing the leader (e.g. Rivas and Sutter 2011; Brandts et al. 2011; Arbak and Villeval 2013). None of these studies have however considered the potential implications in terms of group cohesion from having a leader whose social identity is perceived as different by his or her followers.

Finally, some of the behavioral implications which might result from singling an individual out might also be linked to psychological phenomena which has been studied in the psychological research with respect to social exclusion/inclusion, marginalization, stigmatization, and stereotyping (for an overview of this literature, see Heatherton et al. 2000; Abrams et al. 2005). This literature usually focuses on attitudes rather than behavior (e.g., Sekaquaptewa and Thompson 2002; Thau et al. 2007), and extensively uses deception as a way to manipulate the behavior when the latter is the object of interest (e.g., Twenge et al. 2001, 2007; Derfler-Rozin et al. 2010).

\section{Experimental design}

\subsection{Outline}

The experiment was conducted between March and July 2011 at the University of East Anglia with a total of 324 subjects divided into 54 sessions; there were 6 subjects per session. ${ }^{5}$ The participants were mostly students with a variety of different backgrounds. ${ }^{6}$ The experiment was fully computerized with the z-Tree software (Fischbacher 2007). Subjects received both computerized and printed instructions at the beginning of each experimental task. The presentation of the experimental instructions was as neutral as possible avoiding terms such "trust", "truster", or "trustee". The experiment employed a fictional currency, the experimental credit, which was converted to pounds at the end of the experiment at the rate of 20 UK pence per experimental credit. Subjects earned on average $£ 11.78$ (around 18-19 US dollars), including a show-up fee of $£ 1.50$. Earnings were paid privately and anonymously at subjects' stations at the end of the experiment. Each session lasted around 35 minutes. Subjects were allowed to participate in no more than one session.

\footnotetext{
5 We ran sessions with only 6 players in order to have enough variation in characteristics between sessions and minimize the possibility that specific characteristics were systematically associated to the singled out subject. Further advantages of running the sessions with only 6 players were that of reducing the chances of subjects knowing each other; minimizing the likelihood of subjects seeing and interacting with each other as they arrived, as they were immediately seated, avoiding people queuing at the entrance of the lab; and minimizing the likelihood of the subjects seeing each other as they left; partitions ensured that subjects did not see each other during the experiment.

${ }^{6}$ Details of the socioeconomic background of the experimental participants, and experimental instructions can be found in the online appendix.
} 
The experiment consisted of seven treatments, described below: the baseline (B), the black sheep treatment (BS), the golden sheep treatment (GS), the random sheep treatment (RS), the privately informed black sheep treatment (PIBS), the privately informed golden sheep treatment (PIGS), and the authority and black sheep treatment (ABS). We ran eight sessions per treatment (seven in PIBS and PIGS).

\subsection{Beginning of the experiment and ranking phase}

In each session, subjects were randomly assigned to computer terminals, which were separated by partitions in order to avoid facial or verbal communication between subjects. After being assigned to computer stations, subjects were asked to fill in a questionnaire with their personal information. In particular, we asked subjects to indicate their gender, age, current university status, country of origin, whether their main field of studies was related to Economics or not, their religion, whether they used Facebook or not, their current relationship status, and whether they smoked or not. After completing the questionnaire, subjects received the instructions for the first experimental task (i.e. trust game).

Once everyone had finished reading the instructions, each subject was informed about these characteristics for the other participants, and asked to rank them according to how much she or he would like to be matched with them in the experiment (from the most preferred match to the least preferred match). ${ }^{7}$ Without informing the participants ex ante, the computer allocated to each subject a certain number of points corresponding to the rank assigned by each other participant to that specific individual (i.e. five points for being ranked first, four for being ranked second, and so on), and ordered the subjects from the participant with the most points (the most preferred match) to the one with the least points (the least preferred match) ${ }^{8}$ In other words, the computer applied a Borda count to the individual rankings in order to determine a consensus-based preference ordering of the participants.

A disadvantage of the Borda count is that it may induce strategic behaviors or a false revelation of own preferences. This is not a problem in our experiment because subjects were not informed ex ante about the aggregation procedure and why they had to rank the other participants (i.e. selection of the singled out subject). Furthermore, we are not interested in the results of the Borda count per se, but only as a framing tool to induce singling out.

\subsection{The baseline (B) treatment}

The experimental treatments differed in what followed the ranking phase. ${ }^{9}$ We first describe the B treatment. After all the subjects submitted their rankings, they were not

\footnotetext{
7 Ties in the ranking were not allowed.

8 Ties in the ranking were dealt with by the computer with a random draw.

9 A critical reader might argue that the ranking phase might change later trust game play. However, all we are interested in this paper is across-treatment differences, and these cannot be explained by the ranking phase, which equally preceded all treatments.
} 
told how the computer processed these data. The participants simply proceeded to the next phase. In particular, they filled in a control questionnaire designed to check their understanding of the instructions. Clarifications were individually given to subjects with incorrect answers. The experimental task was a standard Berg et al. (1995)'s trust game. In this set-up, a truster (the first mover) must decide how much to invest/keep of an endowment X (48 experimental credits in our case). Calling the amount invested T, the investment gives $3 \times \mathrm{T}$. This investment's return is sent to the trustee (the second mover) who must decide how to share the received amount with the truster. If she keeps $\mathrm{Y}$, the total payoffs will be $(\mathrm{X}-\mathrm{T})+3 \times \mathrm{T}-\mathrm{Y}$, for the truster, and $\mathrm{Y}$ for the trustee, respectively. T measures the amount of trust, $3 \times \mathrm{T}-\mathrm{Y}$ measures trust fulfilling and therefore, trustworthiness. There were 4 rounds of the trust game. In each round, each subject was matched with a different co-participant (absolute stranger matching). In this way, we avoided reputation building, which could stem from re-matching the same subjects more than once. Each subject was also randomly assigned the role of trustee for half the time and truster for the other half. The randomness of the order in which roles were assigned to subjects enabled us to rule out any effect due to playing first as truster or trustee. In addition, any across-treatment differences cannot be explained by the fact that individuals played both roles since this equally occurred in all treatments. No information about a co-participant (e.g. participant's ID, gender, nationality, and so on) was revealed to the subjects. At the end of each round, each subject was informed about the decision of the counterpart and the experimental credits that he or she could earn if the round were to be selected for the payment.

Once subjects completed this experimental task, a new set of instructions for an incentivized individual task was given. This new task was a standard Holt and Laury (2002) questionnaire in the domain of gains. ${ }^{10}$ The aim of the task was to measure risk attitude by counting the number of times subjects chose the safer option. The task details are in the experimental instructions. A further questionnaire was then given, in two parts. The first part was the 17-item Social Desirability Scale (Stöber 2001). This scale measures the desire to present oneself in a positive light. For each item of the scale, a subject has to decide if the statement describes himself/herself or not (true-or-false type of scale). The second part of the questionnaire was the Rosenberg's (1965) self-esteem scale, widely used in psychology to measure state self-esteem. For each of the ten items of the scale, a subjects has to indicate how much he or she agree with the statement on a four-point scale (from strongly agrees to strongly disagree). Final payments were based on the earnings of one randomly chosen trust game round, plus the earnings from the Holt and Laury (2002) task.

\subsection{Other treatments}

Now we turn to the description of the other treatments. These were identical to the B treatment except in what follows. In the black sheep (BS treatment), after all the subjects submitted their rankings, the computer explained how it processed these data

\footnotetext{
10 Houser et al. (2010) found no evidence for order effects from having the Holt and Laury task played after the trust game and vice versa.
} 
to determine which one was considered the least preferred match in the experiment, i.e. the participant that everyone else least wanted to interact with in the experiment. Subjects were also told that whenever a participant was matched with the least preferred match during the experiment, the least preferred match would be identified with a mark (i.e. an asterisk). The real identity of the least preferred match was not revealed at any point of the experiment. ${ }^{11}$ Through this procedure, we artificially induced an identifiable status of being singled out which was based on consensually undesirable attributes.

The golden sheep (GS) treatment was similar to the BS treatment except that the computer explained how it processed the data on the individual rankings to determine which participant was considered the most preferred match in the experiment, i.e. the participant that everyone else most wanted to interact with in the experiment. Each subject was then informed whether he or she was the most preferred match. The most preferred match was identified with an asterisk during the trust game. In contrast to the BS treatment, the aim of the GS treatment was to induce an artificial identifiable status of being singled out which was based on consensually desirable attributes.

In the privately informed black sheep, PIBS (privately informed golden sheep, PIGS), treatment, after the ranking phase, the computer informed the subjects about how the least (most) preferred match was selected from the individual rankings, and told the least (most) preferred match about his or her status. However, the singled out participant was not marked with an asterisk during the experiment. In other words, the singled out subject could not be identified by the other participants during the trust game. This treatment was designed to disentangle the "pure" effect of being singled out, which comes from the personal recognition of the singled out subject to be consensually disliked (liked), from the effect of being identifiable as the singled out subject by the others.

In the authority and black sheep (ABS) treatment, after the ranking phase, the computer informed the subjects that the individual ranking of one randomly selected participant from the experiment (i.e. the authority) determined who was considered the least preferred match in the experiment. In particular, the least preferred match was the participant that the authority least wanted to interact with in the experiment according to his or her individual ranking. As in the BS treatment, the least preferred match was identified with an asterisk. Subjects were also told whether they were the authority or not, and that the authority could not be matched with the least preferred match during the experiment. This is because we wanted to isolate the behavioral reaction of the singled out subject towards those who were not responsible of his or her status. Note that in the ABS treatment we were not interested in identifying and inducing a real status of being authority. Indeed, what we refer as the authority is simply an individual randomly selected by the computer. Here, we simply wanted to investigate the effects

\footnotetext{
11 Our subjects were recruited using the ORSEE software (Greiner 2004) from the UEA subject pool of over 1,000 potential participants, thus ensuring a systematic randomization of the participants while at the same time minimizing the probability that among the 6 subjects there were acquaintances that could pick up on specific combinations of characteristics to identify co-participants. Importantly, while information was provided on subjects during the ranking phase, once a singled out subject was picked up, we did not reveal his or her individual characteristics on the screen. Overall, there is therefore good reason to believe that subjects did not know who the singled out subject was.
} 
Table 1 Features of experimental treatments

\begin{tabular}{lllll}
\hline Treatment & Sessions & Asterisk & Social standing & Being responsible \\
\hline B & 8 & NO & NO & - \\
BS & 8 & YES & Negative & YES \\
GS & 8 & YES & Positive & YES \\
RS & 8 & YES & Neutral & NO \\
PIBS & 7 & NO & Negative & YES \\
PIGS & 7 & NO & Positive & YES \\
ABS & 8 & YES & Negative & NO \\
\hline
\end{tabular}

of singling a member out, under a negative frame, when a specific individual rather than the whole group is responsible of such decision. This treatment, together with the RS treatment, enabled us to test the implications on trust and trustworthiness of shifting the responsibility for the condition of the singled out individual to someone else.

Finally, in the random sheep (RS) treatment, subjects were simply told that one of them was going to be randomly singled out by the computer and identified with an asterisk for the rest of the experiment. Hence, here the status of being singled out was not associated to a negative nor a positive social standing. This treatment was designed to pick up the effect of a random attribution of distinctiveness under a neutral frame, and when no participant was responsible for such attribution.

As noted earlier, these treatments were identical to the B treatment except for the points noted above, e.g. subjects filled in an initial control questionnaire designed to check their understanding of the instructions, and had a Holt and Laury (2002) and a psychological questionnaire at the end. Table 1 summarizes the main features of our treatments. In BS, we artificially induced a negative identifiable status of being singled out in order to study its implications on trust and trust fulfilling within a group of individuals. GS was identical to BS except that we artificially induced a positive identifiable status of being singled out. In PIBS and PIGS, we controlled for the possible effect that being identifiable as singled out subject has on the behavior of this latter individual. In other words, we removed the effect of identification. RS tested whether the identification mark per se affects the behavior of the singled out subject, when no other subject is responsible for his or her status. Finally, in ABS we investigated the implications of having a singled out member within a group of subjects when a specific subject is the only one to blame for the status of the singled out individual.

\section{Behavioral conjectures}

To understand the consequences of singling an agent out, we consider the following individual's utility function that linearly depends on the own $\left(\pi_{O}\right)$ and counterpart's $\left(\pi_{C}\right)$ monetary payoffs: ${ }^{12}$

$$
U_{O}\left(\pi_{O}, \pi_{C}\right)=w_{O} \pi_{O}+w_{C} \pi_{C}
$$

\footnotetext{
12 This utility function was proposed by Charness and Rabin (2002) to capture social preferences and extended by Chen and $\mathrm{Li}$ (2009) to incorporate group identity.
} 
$w_{O}$ and $w_{C}$ are the weights that the individual puts on the own and counterpart's payoffs respectively, with $w_{C}=1-w_{O}$. We assume that the weight that the individual places on the own payoffs depends on a series of elements (e.g. fairness, reciprocity) including the social distance of the two individuals, by which we mean the degree of demographic similarity between the two agents (Buchan et al. 2006). ${ }^{13}$

To formalize this, let $I_{O}$ be the social distance of the individual with respect to the counterpart and $\theta_{O}$ all other elements that affects the weight. We can rewrite the utility function as

$$
U_{O}\left(\pi_{O}, \pi_{C}\right)=w_{O}\left(I_{O}, \theta_{O}\right) \pi_{O}+\left[1-w_{O}\left(I_{O}, \theta_{O}\right)\right] \pi_{C}
$$

where $\partial w_{O} / \partial I_{O} \leq 0$ and $\partial w_{O} / \partial \theta_{O} \geq 0$ for any $I_{O}$ and $\theta_{O} . \theta_{O}$ is a parameter that captures the distribution and other-regarding preferences of the individual, other than those related to social distance. $\theta_{O}$ can, for example, identify the charity concern of the individual when his or her payoff is higher than his or her counterpart's payoff or the envy when his or her payoff is lower than his or her counterpart's payoff (see Charness and Rabin 2002; Chen and Li 2009); it can also capture reciprocity concerns. If $\partial w_{O} / \partial \theta_{O}=0$, the individual does not care about other-regarding preferences not captured by $I_{O}$.

If $\partial w_{O} / \partial I_{O}=0$, the individual does not care about social distance; the more negative $\partial w_{O} / \partial I_{O}$ is, the more the individual cares about social distance and the more he or she will weigh the own payoff compared to the counterpart's payoff. In terms of our manipulation, this means that non-singled out subjects will weigh the payoff of the singled out subject less compared to other non-singled out individuals. This is because they will perceive the singled out subject as socially distant from them. As a result, non-singled out subjects will treat the singled out subject worse than other individuals (see, for example, Hargreaves-Heap and Zizzo 2009), especially if the subject is singled out because of his or her undesirable qualities. At the same time, the presence of a singled out subject will strengthen the feelings of in-group inclusion of the other members (Pickett and Brewer 2005), thus inducing reciprocal favoritism among those individuals. Similarly, the member who has been singled out will give and return less compared to other individuals because he or she no longer feels any bond with the other members. Hence, the first two conjectures (social distance conjectures) are as follows.

Conjecture 1 When the condition of singled out is made salient, non-singled out members will give and return less (more) to the singled out individual (to other nonsingled out individuals).

Conjecture 2 The singled out individual will be less trusting and trustworthy compared to other individuals.

\footnotetext{
13 Two individuals may differ in many demographic characteristics, such as age, gender, ethnicity, social status, class, etc. Social distance captures the extent to which they are overall different. It can be also measured in terms of group identity (Charness et al. 2007; Buchan et al. 2006). In particular, two individuals are socially closer if they belong to the same social group and more distant if they do not belong to the same group (Buchan et al. 2006).
} 
Conjecture 1 may be sensitive to whether the responsibility of singling a member out is attributable or not to the non-singled out individual interacting with the singled out member. In particular, in the former case, non-singled out subjects might experience guilt and distress for the singled out subject's condition. This is what Charness (2000, p. 375), in a different context, called the responsibility-alleviation effect, i.e. a mitigation of "internal impulses toward honesty, loyalty, or generosity" because of "shifting the responsibility for an outcome to an external authority". In the context of singling out, this means that non-singled out individuals, who can be held responsible for the condition of the singled out individual, might feel guilty, and, therefore, less inclined to treat him or her worse than the others. In other words, this psychological effect counterbalances the effect of perceiving the singled out individual as an outsider (Conjecture 1). The result is that, when the non-singled out individuals can be held responsible for the status of the singled out individual, the two effects may cancel out and therefore we should observe no discrimination. On the other hand, when they cannot be held responsible, there is no guilt involved, and, therefore, we should observe negative discrimination that stems from perceiving the singled out individual as an outsider. Hence, in complement to Conjecture 1, we also consider the following conjecture (responsibility conjecture).

Conjecture 3 Non-singled out members interacting with the singled out individual will give and return less to him/her than non-singled out individuals, only when they are not responsible for his or her condition.

In opposition to Conjecture 2, it is also possible that the member, who has been singled out because of his or her undesirable qualities, will trust and fulfill trust more in order to demonstrate his or her social value to the others. Such behavior would be consistent with some studies in social psychology showing that individuals who are at the risk of exclusion engage in pro-social behavior in order to reconnect with the others (e.g. Derfler-Rozin et al. 2010). In terms of our utility function, this means that the individual who is consensually disliked in the group will weigh the payoff of the counterpart more than other individuals will do. In a similar fashion but for a different reason, the weight that the consensually liked member put on the payoff of the counterpart may be larger than the weight put by other members. This is because he or she may perceive his or her relationship with the others as an intra-group relationship where he or she fulfill a special role, with a greater responsibility for the wealth of the group due to the higher status' attribution. Hence, consistently with some of the findings of the psychological research on leadership theory (e.g. Hogg 2001), the positively singled out individual may display in-group favoritism towards the other individuals and, therefore, be less selfish or adopt pro-social behaviors. Taking these considerations into account, we can devise the following conjecture, opposed to Conjecture 2, regarding the behavior of the singled out individual (social standing conjecture):

Conjecture 4 The negatively (positively) singled out individual will be more trusting and trustworthy compared to other individuals.

Note that all the aforementioned conjectures are related to the pure effect of singling out and abstract from the individual characteristics of the singled out individuals. As 
Table 2 Giving and return rates to singled out and non-singled out

\begin{tabular}{lllllllll}
\hline & B & BS & GS & RS & PIBS & PIGS & ABS & Tot. \\
\hline Giving rate* & 0.400 & 0.387 & 0.398 & 0.402 & 0.367 & 0.405 & 0.400 & 0.394 \\
To singled out & - & 0.354 & 0.318 & 0.284 & - & - & 0.387 & 0.336 \\
To non-singled out** & - & 0.422 & 0.421 & 0.456 & - & - & 0.432 & 0.414 \\
Return rate* & 0.244 & 0.138 & 0.210 & 0.204 & 0.162 & 0.195 & 0.184 & 0.191 \\
To singled out & - & 0.216 & 0.198 & 0.142 & - & - & 0.100 & 0.165 \\
To non-singled out** & - & 0.147 & 0.212 & 0.201 & - & - & 0.246 & 0.206 \\
\hline
\end{tabular}

Tot total

* Overall giving/return rate

** Giving/return rate of non-singled out subjects to non-singled out subjects

our experiment induces the status of being singled out artificially, we are able to provide a powerful test of these conjectures ruling out any explanations that stem from the particular individual characteristics of the singled out individual. In particular, we can test for Conjecture 1, by comparing the behavior of non-singled out subjects towards the singled out individual and other non-singled subjects with the behavior of baseline subjects. If Conjecture 1 is sensitive to the responsibility-alleviation effect (Conjecture 3), we should observe a drop in trust and/or trustworthiness of non-singled out subjects towards the singled out individual only in ABS and RS. Finally, Conjectures 2 and 4 can be tested by looking at the behavior of the singled out subject compared to baseline subjects. On this respect, our control treatments PIBS and PIGS allow us to test the "pure" effect of being singled out, removing any effects that stem from being identifiable as the singled out subject by the others.

\section{Experimental results}

Our focus in this paper is on the results of the trust games. ${ }^{14}$ The giving rate identifies the proportion of endowment that the truster transfers to the trustee, while the return rate measures the amount returned by the trustee to the truster as a fraction of the total amount received from the truster (i.e. three times the amount given by the truster).

Tables 2 and 3 show average giving and return rates for each experimental treatment, while Fig. 1 displays giving and return rates for each experimental treatment. Note that, while Table 3 provides information on most and least preferred subjects in the baseline for comparison with the other treatments, most and least preferred subjects in this treatment were not singled out. ${ }^{15}$

\footnotetext{
$\overline{14}$ We have also analyzed matching preferences as revealed in our unincentivized initial ranking phase. These are presented in the online appendix. Throughout the paper, except where otherwise specified, session averages are used as the unit of observation for bivariate statistical tests (the reported $p$ values are two tailed), and individual averages as the unit of observation for the regression analysis.

15 If we focus on the baseline subjects, and compare the behavior of both the least and most preferred baseline matches with the behavior of the other baseline participants, we do not detect any statistically significant difference in mean giving and return rates (Wilcoxon $p>0.1$ ).
} 
Table 3 Giving and return rates from singled out, non-singled out, and authority

\begin{tabular}{|c|c|c|c|c|c|c|c|c|c|}
\hline & B & & BS & GS & RS & PIBS & PIGS & ABS & Tot. \\
\hline Giving rate* & 0.400 & & 0.387 & 0.398 & 0.402 & 0.367 & 0.405 & 0.400 & 0.394 \\
\hline From 'singled out'** & $0.500^{\mathrm{a}}$ & $0.413^{\mathrm{b}}$ & 0.280 & 0.385 & 0.307 & 0.412 & 0.329 & 0.387 & 0.349 \\
\hline From non-singled out $* * *$ & - & & 0.422 & 0.421 & 0.456 & 0.358 & 0.420 & 0.432 & 0.414 \\
\hline From authority & - & & - & - & - & - & - & 0.331 & 0.331 \\
\hline Return rate* & 0.244 & & 0.138 & 0.210 & 0.204 & 0.162 & 0.195 & 0.184 & 0.191 \\
\hline From 'singled out'** & $0.320^{\mathrm{a}}$ & $0.283^{b}$ & 0.037 & 0.211 & 0.260 & 0.073 & 0.204 & 0.211 & 0.164 \\
\hline From non-singled out ${ }^{* * *}$ & - & & 0.147 & 0.212 & 0.201 & 0.185 & 0.193 & 0.246 & 0.206 \\
\hline From authority & - & & - & - & - & - & - & 0.078 & 0.078 \\
\hline
\end{tabular}

Tot total, $B$ baseline

* Overall giving/return rate

** Giving/return rate from most preferred and least preferred subjects to non-singled out subjects; most preferred or least preferred subjects were singled out in all treatments except the B treatment, for which values are provided as controls

*** Giving/return rate of non-singled out subjects to non-singled out subjects

${ }^{\text {a }}$ Giving/return rate from the least preferred baseline subject

${ }^{\mathrm{b}}$ Giving/return rate from the most preferred baseline subject

To verify treatment effects, controlling for different covariates, we conduct a regression analysis on mean giving and return rate by each subject. ${ }^{16}$ In particular,we employ Tobit regressions ${ }^{17}$ with clustered robust standard errors in order to control for the possible non-independence of the observations within a same session. ${ }^{18}$ Regressions 1-2 in Table 4 and regressions 3-4 in Table 5 use the mean giving and return rate respectively to non-singled out subjects as dependent variable, while regressions 5-6 in Table 6 and regressions 7-8 in Table 7 use respectively the giving and return rate to singled out subjects. ${ }^{19}$ This distinction between giving/return rate to non-singled

\footnotetext{
16 The $i$ observation on the giving/return rate corresponds to the average giving/return rate of the $i$-th subject over the two rounds of the trust game where the subject played as truster/trustee (note from the design section that each subject played two times in the role of truster and two times in the role of trustee in a random order). We use individual averages in order to control for the non-independence of the observations at individual level. Note in fact that we have two potential levels of non-independence: at individual and session level. By taking the individual mean giving and return rates, we control for the first. This simplifies our estimation, reducing potential endogeneity issues and providing more comparable results with previous studies (e.g. Hargreaves-Heap and Zizzo 2009, Tsustui and Zizzo, in press). In the on-line appendix, we also report the results of Tobit regressions with clustered robust standard errors at subject level or session level, and multilevel mixed-effects linear regressions, where the unit of observation is the round. The results of these regressions are qualitatively similar to those reported in the paper. However, they do not fully control for the non-independence of the observations or the censored nature of the data, leaving the regressions reported in the paper as a better estimation option.

17 Giving and return rates lie between 0 and 1.

18 We have also conducted random effects regressions, which however, generally failed to pass the Hausman diagnostic test. The only regressions that did pass the Hausman diagnostic test are on the giving rate to non-singled out and singled out subjects. Their results broadly replicate those in the paper.

19 Note that each subject could not interact with a singled out individual (or any other subject) more than once. Hence, each observation of regressions $7-8$, in a treatment where the singled out was identified by an
} 


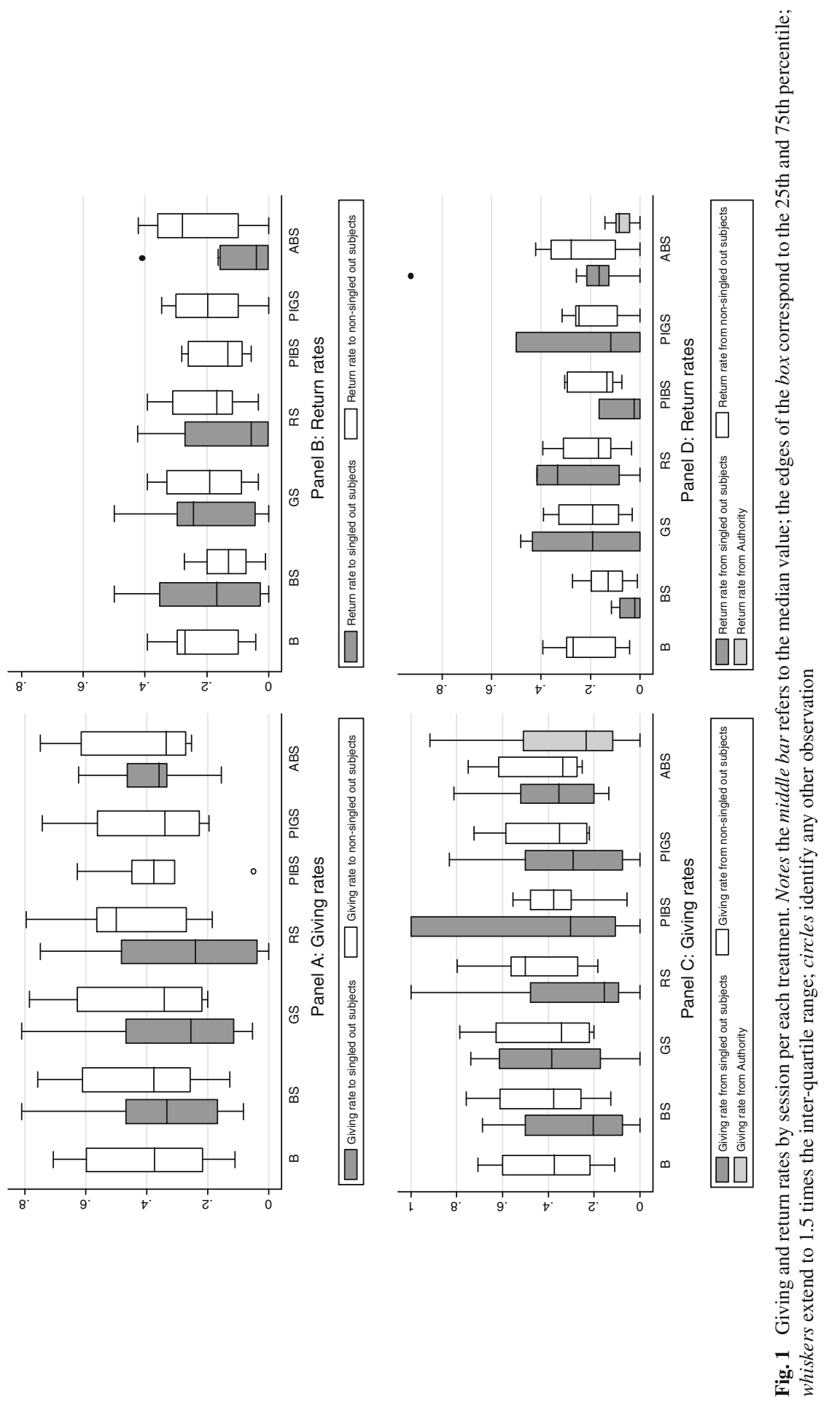


Table 4 Regressions on giving rate to non-singled out subjects

\begin{tabular}{|c|c|c|c|c|c|c|}
\hline & \multicolumn{3}{|l|}{ Regression 1} & \multicolumn{3}{|l|}{ Regression 2} \\
\hline & $\mathrm{b}$ & SE & $p$ & $\mathrm{~b}$ & SE & $p$ \\
\hline All treatments & & & & -0.01 & 0.1 & 0.919 \\
\hline $\mathrm{BS}+\mathrm{PIBS}$ & -0.059 & 0.11 & 0.594 & & & \\
\hline GS + PIGS & 0.016 & 0.11 & 0.887 & & & \\
\hline $\mathrm{RS}$ & 0 & 0.12 & 0.997 & & & \\
\hline ABS & 0.022 & 0.11 & 0.847 & & & \\
\hline Singled out in RS & -0.081 & 0.08 & 0.301 & -0.066 & 0.12 & 0.585 \\
\hline Singled out in ABS & -0.001 & 0.07 & 0.984 & 0.031 & 0.08 & 0.684 \\
\hline Singled out in BS and PIBS & -0.02 & 0.12 & 0.868 & -0.066 & 0.12 & 0.576 \\
\hline Singled out in GS and PIGS & -0.098 & 0.06 & 0.128 & -0.071 & 0.08 & 0.36 \\
\hline Selector & -0.103 & 0.15 & 0.494 & -0.073 & 0.13 & 0.579 \\
\hline Risk Aversion & -0.005 & 0.01 & 0.596 & -0.007 & 0.01 & 0.496 \\
\hline SDS17 Score & -0.015 & 0.01 & 0.117 & -0.015 & 0.01 & 0.12 \\
\hline RSE Score & -0.004 & 0 & 0.37 & -0.004 & 0 & 0.408 \\
\hline Age & 0.009 & 0.01 & 0.175 & 0.009 & 0.01 & 0.16 \\
\hline Gender & 0.037 & 0.04 & 0.321 & 0.033 & 0.04 & 0.385 \\
\hline Economics & $-0.113^{* *}$ & 0.05 & 0.022 & $-0.111^{* *}$ & 0.05 & 0.027 \\
\hline UK & -0.051 & 0.05 & 0.268 & -0.053 & 0.05 & 0.251 \\
\hline India & $-0.206^{* * *}$ & 0.07 & 0.002 & $-0.199 * * *$ & 0.07 & 0.003 \\
\hline Christian & $-0.07 *$ & 0.04 & 0.087 & $-0.076^{*}$ & 0.04 & 0.056 \\
\hline Muslim & $-0.334 * * * *$ & 0.09 & 0 & $-0.333^{* * * *}$ & 0.09 & 0 \\
\hline Single & $0.084^{*}$ & 0.04 & 0.051 & $0.089^{* *}$ & 0.04 & 0.041 \\
\hline Smoker & 0.019 & 0.08 & 0.804 & 0.029 & 0.08 & 0.705 \\
\hline $\mathrm{PhD}$ & 0.035 & 0.08 & 0.651 & 0.037 & 0.08 & 0.64 \\
\hline Constant & 0.221 & 0.19 & 0.253 & 0.228 & 0.18 & 0.212 \\
\hline Obs & 324 & & & 324 & & \\
\hline Pseudo R-sqr & 0.091 & & & 0.086 & & \\
\hline Df & 302 & & & 305 & & \\
\hline Prob $>F$ & 0 & & & 0 & & \\
\hline
\end{tabular}

Tobit regression with clustered robust standard errors

${ }^{*} p<0.1,{ }^{* *} p<0.05,{ }^{* * *} p<0.01,{ }^{* * * *} p<0.001$

out subjects and giving/return rate to singled out subjects allows us to test whether singled out subjects discriminate against non-singled out subjects and/or the reverse relative to the Baseline treatment. In particular, they allow us to separate individual decisions made when a subject was matched with a singled out individual and with a non-singled out individual.

The regressions employ dummy variables for the experimental treatments, either individually ( $\mathrm{BS}=1$ for $\mathrm{BS}$ treatment observations, and similarly for GS, RS, PIBS,

Footnote 19 continued

asterisk, is not an average across two rounds but corresponds to the giving/return rate of a non-singled out subject interacting with a singled out subject. 
Table 5 Regressions on return rate to non-singled out subjects

\begin{tabular}{|c|c|c|c|c|c|c|}
\hline & \multicolumn{3}{|l|}{ Regression 3} & \multicolumn{3}{|l|}{ Regression 4} \\
\hline & $\mathrm{b}$ & SE & $p$ & $\mathrm{~b}$ & SE & $p$ \\
\hline Trust rate as trustee & $0.406^{* * * * *}$ & 0.06 & 0.000 & $0.409 * * * *$ & 0.06 & 0.000 \\
\hline All treatments & & & & $-0.076^{*}$ & 0.04 & 0.052 \\
\hline $\mathrm{BS}+\mathrm{PIBS}$ & $-0.107 * *$ & 0.05 & 0.026 & & & \\
\hline GS + PIGS & $-0.078^{*}$ & 0.05 & 0.091 & & & \\
\hline RS & -0.041 & 0.06 & 0.487 & & & \\
\hline ABS & -0.047 & 0.07 & 0.496 & & & \\
\hline Singled out in RS & 0.105 & 0.11 & 0.359 & 0.143 & 0.10 & 0.141 \\
\hline Singled out in ABS & 0.109 & 0.13 & 0.398 & 0.138 & 0.10 & 0.185 \\
\hline Singled out in BS and PIBS & $-0.129 * * *$ & 0.05 & 0.007 & $-0.160 * * *$ & 0.05 & 0.001 \\
\hline Singled out in GS and PIGS & 0.064 & 0.08 & 0.420 & 0.060 & 0.07 & 0.418 \\
\hline Authority & $-0.170^{* * * *}$ & 0.05 & 0.000 & $-0.143 * * * *$ & 0.04 & 0.001 \\
\hline Risk Aversion & 0.004 & 0.01 & 0.574 & 0.002 & 0.01 & 0.742 \\
\hline SDS17 Score & -0.005 & 0.01 & 0.379 & -0.006 & 0.01 & 0.332 \\
\hline RSE Score & $-0.007 *$ & 0.00 & 0.094 & -0.006 & 0.00 & 0.127 \\
\hline Authority $\times$ SDS17 & $0.048 * * *$ & 0.02 & 0.003 & $0.048 * * *$ & 0.02 & 0.002 \\
\hline Authority $\times$ RSE & 0.004 & 0.01 & 0.471 & 0.003 & 0.01 & 0.514 \\
\hline Authority $\times$ Risk Aversion & -0.008 & 0.02 & 0.653 & -0.006 & 0.02 & 0.711 \\
\hline Age & 0.003 & 0.01 & 0.630 & 0.003 & 0.00 & 0.594 \\
\hline Gender & 0.011 & 0.03 & 0.718 & 0.009 & 0.03 & 0.761 \\
\hline Economics & $-0.083^{* *}$ & 0.04 & 0.049 & $-0.081 * *$ & 0.04 & 0.047 \\
\hline UK & -0.060 & 0.05 & 0.185 & -0.060 & 0.05 & 0.193 \\
\hline India & -0.058 & 0.06 & 0.323 & -0.056 & 0.06 & 0.350 \\
\hline Christian & -0.002 & 0.04 & 0.958 & -0.007 & 0.04 & 0.845 \\
\hline Muslim & -0.118 & 0.08 & 0.161 & -0.122 & 0.08 & 0.146 \\
\hline Single & $0.067^{* *}$ & 0.03 & 0.024 & $0.067 * *$ & 0.03 & 0.021 \\
\hline Smoker & -0.012 & 0.04 & 0.758 & -0.009 & 0.04 & 0.817 \\
\hline $\mathrm{PhD}$ & -0.013 & 0.06 & 0.821 & -0.010 & 0.06 & 0.856 \\
\hline Constant & 0.151 & 0.14 & 0.273 & 0.152 & 0.12 & 0.217 \\
\hline Obs & 307 & & & 307 & & \\
\hline Pseudo R-sqr & 0.393 & & & 0.382 & & \\
\hline Df & 281 & & & 284 & & \\
\hline Prob $>$ F & 0.000 & & & 0.000 & & \\
\hline
\end{tabular}

Tobit regression with clustered robust standard errors

${ }^{*} p<0.1,{ }^{* *} p<0.05,{ }^{* * *} p<0.01,{ }^{* * * *} p<0.001$

PIGS and $\mathrm{ABS})$ or in combination $(\mathrm{RS}+\mathrm{ABS}=1$ for $\mathrm{RS}$ or $\mathrm{ABS}$ treatments observations, ${ }^{20}$ and similarly for BS + PIBS and for GS + PIGS). In regressions 2 and 4 we

\footnotetext{
20 The singled out subject was selected by the computer (i.e. through a random draw) in RS, and by the authority (i.e. the participant whose individual ranking determined who was considered the least preferred
} 
Table 6 Regressions on giving rate to singled out subjects

\begin{tabular}{|c|c|c|c|c|c|c|}
\hline & \multicolumn{3}{|l|}{ Regression 5} & \multicolumn{3}{|l|}{ Regression 6} \\
\hline & $\mathrm{b}$ & SE & $p$ & $b$ & SE & $p$ \\
\hline Asterisk & & & & -0.127 & 0.11 & 0.27 \\
\hline BS & -0.067 & 0.14 & 0.638 & & & \\
\hline GS & -0.127 & 0.15 & 0.404 & & & \\
\hline PIBS & -0.07 & 0.12 & 0.57 & -0.071 & 0.12 & 0.566 \\
\hline PIGS & -0.013 & 0.12 & 0.917 & -0.012 & 0.12 & 0.921 \\
\hline $\mathrm{RS}+\mathrm{ABS}$ & -0.157 & 0.13 & 0.222 & & & \\
\hline Risk aversion & -0.008 & 0.01 & 0.568 & -0.006 & 0.01 & 0.63 \\
\hline SDS17 Score & -0.007 & 0.01 & 0.512 & -0.007 & 0.01 & 0.527 \\
\hline RSE Score & -0.006 & 0.01 & 0.367 & -0.006 & 0.01 & 0.376 \\
\hline Age & 0.013 & 0.01 & 0.149 & 0.013 & 0.01 & 0.156 \\
\hline Gender & -0.022 & 0.06 & 0.7 & -0.023 & 0.06 & 0.677 \\
\hline Economics & $-0.15^{*}$ & 0.08 & 0.064 & $-0.156^{*}$ & 0.08 & 0.056 \\
\hline UK & -0.036 & 0.07 & 0.607 & -0.035 & 0.07 & 0.611 \\
\hline India & $-0.220^{* *}$ & 0.09 & 0.014 & $-0.215^{*}$ & 0.09 & 0.013 \\
\hline Christian & -0.049 & 0.06 & 0.421 & -0.045 & 0.06 & 0.459 \\
\hline Muslim & $-0.434 * * *$ & 0.14 & 0.002 & $-0.431 * * *$ & 0.14 & 0.002 \\
\hline Single & 0.061 & 0.06 & 0.298 & 0.059 & 0.06 & 0.323 \\
\hline Smoker & 0.058 & 0.11 & 0.593 & 0.053 & 0.11 & 0.628 \\
\hline $\mathrm{PhD}$ & -0.119 & 0.09 & 0.208 & -0.121 & 0.09 & 0.203 \\
\hline Constant & 0.18 & 0.23 & 0.437 & 0.189 & 0.23 & 0.408 \\
\hline Obs & 196 & & & 196 & & \\
\hline R-sqr & 0.086 & & & 0.084 & & \\
\hline Df & 178 & & & 180 & & \\
\hline Prob $>F$ & 0.015 & & & 0.009 & & \\
\hline
\end{tabular}

Tobit regression with clustered robust standard errors

${ }^{*} p<0.1,{ }^{* *} p<0.05,{ }^{* * *} p<0.01,{ }^{* * * *} p<0.001$

use a single dummy variable ("All Treatments") for all treatments with a singled out subject; in regressions 6 and 8 we employ a single dummy variable ("Asterisk") for all treatments where the singled out was identified by an asterisk. In regressions 1-4 we also employ dummy variables, one for each treatment, which take value 1 if the subject was a singled out subjects in BS and PIBS or alternatively in GS and PIGS; ${ }^{21}$

Footnote 20 continued

match) in ABS: in both treatment s subjects matched with the singled out individual were not responsible for her/his status. In a bivariate test, we find no statistically significant evidence of a different mean giving/return rate to singled out subjects between the two treatments (Mann-Whitney $p>0.1$ ). Hence, we employ a unique dummy to identify both RS and ABS treatment in regressions 5 and 7 (i.e. giving and return rate to singled out subjects).

21 Giving/return rates of singled out subjects in BS and PIBS display a similar pattern (Mann-Whitney $p>0.1$ ), as do the giving/return rates in GS and PIGS (Mann-Whitney $p>0.1$ ). 
Table 7 Regressions on return rate to singled out subjects

\begin{tabular}{|c|c|c|c|c|c|c|}
\hline & \multicolumn{3}{|l|}{ Regression 7} & \multicolumn{3}{|c|}{ Regression 8} \\
\hline & $\mathrm{b}$ & SE & $p$ & $\mathrm{~b}$ & SE & $p$ \\
\hline Trust rate as trustee & $0.437 * * * *$ & 0.08 & 0.000 & $0.416^{* * * *}$ & 0.07 & 0.000 \\
\hline Asterisk & & & & $-0.130 * * *$ & 0.05 & 0.005 \\
\hline BS & -0.016 & 0.09 & 0.858 & & & \\
\hline GS & -0.063 & 0.06 & 0.297 & & & \\
\hline PIBS & -0.070 & 0.04 & 0.109 & $-0.076^{*}$ & 0.04 & 0.087 \\
\hline PIGS & -0.082 & 0.06 & 0.157 & -0.091 & 0.06 & 0.119 \\
\hline $\mathrm{RS}+\mathrm{ABS}$ & $-0.201 * * * *$ & 0.06 & 0.000 & & & \\
\hline Risk aversion & -0.004 & 0.01 & 0.606 & -0.002 & 0.01 & 0.766 \\
\hline SDS17 Score & 0.005 & 0.01 & 0.433 & 0.004 & 0.01 & 0.496 \\
\hline RSE Score & -0.005 & 0.00 & 0.330 & -0.005 & 0.00 & 0.231 \\
\hline Age & 0.007 & 0.01 & 0.245 & 0.007 & 0.01 & 0.239 \\
\hline Gender & -0.027 & 0.04 & 0.448 & -0.020 & 0.04 & 0.575 \\
\hline Economics & -0.048 & 0.05 & 0.323 & -0.063 & 0.05 & 0.195 \\
\hline UK & 0.031 & 0.05 & 0.532 & 0.024 & 0.05 & 0.623 \\
\hline India & -0.077 & 0.05 & 0.140 & $-0.098^{*}$ & 0.05 & 0.054 \\
\hline Christian & -0.048 & 0.04 & 0.199 & -0.049 & 0.04 & 0.195 \\
\hline Muslim & $-0.138^{*}$ & 0.08 & 0.098 & -0.094 & 0.09 & 0.312 \\
\hline Single & 0.032 & 0.04 & 0.371 & 0.036 & 0.04 & 0.326 \\
\hline Smoker & 0.018 & 0.05 & 0.717 & 0.013 & 0.05 & 0.799 \\
\hline $\mathrm{PhD}$ & 0.037 & 0.07 & 0.586 & 0.031 & 0.07 & 0.657 \\
\hline Constant & 0.056 & 0.14 & 0.695 & 0.047 & 0.15 & 0.754 \\
\hline Obs & 179 & & & 179 & & \\
\hline Pseudo R-sqr & 0.491 & & & 0.438 & & \\
\hline $\mathrm{Df}$ & 160 & & & 162 & & \\
\hline Prob $>F$ & 0.000 & & & 0.000 & & \\
\hline
\end{tabular}

Tobit regression with clustered robust standard errors ${ }^{*} p<0.1,{ }^{* *} p<0.05,{ }^{* * *} p<0.01,{ }^{* * * *} p<0.001$

we also use a further dummy variable for the authority (Authority $=1$ for authorities). In the return rate regressions (Tables 5, 7), an extra explanatory variable is the giving rate received by the trustee. ${ }^{22}$ All the regressions include demographic variables, such as age, gender (=1 for men), economics background (=1 if applicable), nationality ( $U K=1$ for $U K$ subjects, and India $=1$ for Indian subjects), religion (Christian $=1$ for Christian subjects, Muslim +1 for Muslim subjects), whether the subject smokes or not (Smoker +1 for smoker subjects), whether the subject is a MPhil/PhD student or not $(\mathrm{PhD}=1$ for MPhil/PhD students) and relationship status (Single $=1$ for sub-

\footnotetext{
22 The return rate may in fact depend on the amount sent by the truster, i.e. the giving rate of the trustee's counterpart. This is because of several psychological reasons such as inequality aversion (Fehr and Schmidt 1999), reciprocity (Falk and Fischbacher 2006), and trust responsiveness (Guerra and Zizzo 2004).
} 
jects who were not in a relationship or were unmarried), and psychological measures (i.e. social desirability, self-esteem, and risk attitude) ${ }^{23}$ In the regressions of Table 5 , we added interaction terms between Authority and the psychological measures. ${ }^{24}$

Table 4 If we first consider the findings regarding the giving rate to non-singled out subjects, none of the treatment dummies is statistically significant. Among the dummy variables identifying the giving rates from singled out subjects, none of them is statistically significant. This brings us to the following result that does not seem to support Conjecture 1 with respect to trusting behavior.

Result 1 The presence of singled out subjects did not affect mean giving rates to non-singled out subjects.

Table 5 Turning to the return rate to non-singled out subjects, and in line with previous findings on trust games, the giving rate from the truster are found to positively affect the return rate of the trustee $(p=0.000)$. We also find that the least preferred match, in line with Conjecture 2, and the authority returned significantly less than other subjects $(p<0.01)$.

Result 2 Least preferred singled out subjects, and authorities, were less trustworthy than baseline subjects.

In contrast, there is no evidence that the return rates from the most preferred singled out subjects in GS and PIGS treatments were different from those of baseline subjects. Hence, we reject both Conjectures 2 and 4 with respect to the trustworthiness of the most preferred singled out individual.

However, a closer look at the distribution of the mean return rates (Fig. 2) reveals why the dummy 'Singled out in GS and PIGS' does not turn to be statistically significant. In BS and PIBS singled out subjects display only low return rates (between 0 and 0.117 in BS, and 0 and 0.167 in PIBS), while Fig. 2 shows a different, bimodal pattern for GS and PIGS, with either high or low return rates. ${ }^{25}$ We can therefore derive the following result, which, relatively to trustworthiness, partially supports both Conjectures 2 and 4 .

\footnotetext{
23 We do not introduce a dummy variable for Facebook use since only 7 subjects out of 324 in our sample stated that they do not use Facebook. Also, since the risk elicitation task was administered at the end of the experiment, it is possible that subjects made more or less risky choices depending on their expected earnings obtained in the trust game. If such a bias exists, we should observe a correlation between our measure of risk aversion and the expected payoffs from the trust game. However, this correlation is low and not significant (Spearman $\rho=0.013, p=0.818$ ). Hence, we conclude that there is no evidence of systematic bias in measuring risk aversion. Finally, we have also tried other specifications where we have included interactions of the dummies for most and least preferred subjects with dummies related to those attributes (i.e. $\mathrm{UK}$, single, $\mathrm{PhD}$ ) which were more likely to characterize least and most preferred subjects (see section $\mathrm{E}$ of the online appendix, and section 4 of the paper). None of these interaction terms resulted significant.

24 In all the regressions, all the psychological variables as well as the 'Trust Rate as Trustee' variable are centered in order to control for the high correlation between the independent variables. In other words, we subtract the mean from every observation. For a discussion, see Marquardt 1980.

25 BS and PIBS return rates have a standard deviation respectively of 0.049 and 0.082 , while in B return rates are smoothly distributed between 0.042 and 0.392 with a standard deviation of 0.125 . In contrast, the return rates lie between 0 and 0.483 in GS and between 0 and 0.5 in PIGS, with a standard deviation respectively of 0.224 and 0.226 .
} 

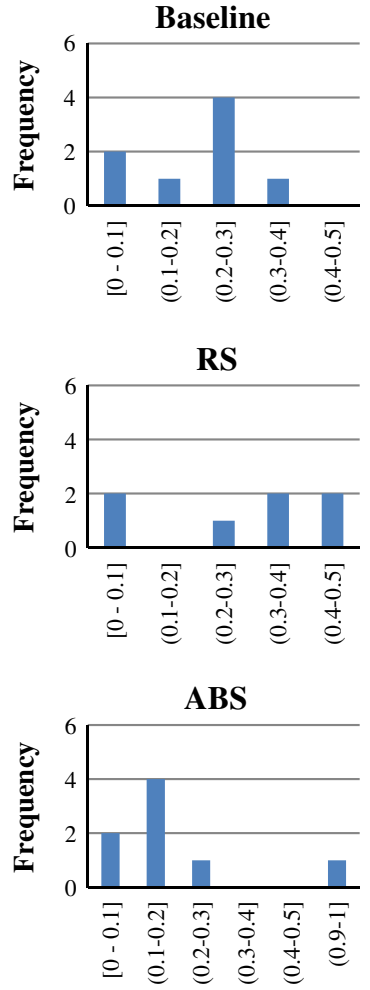
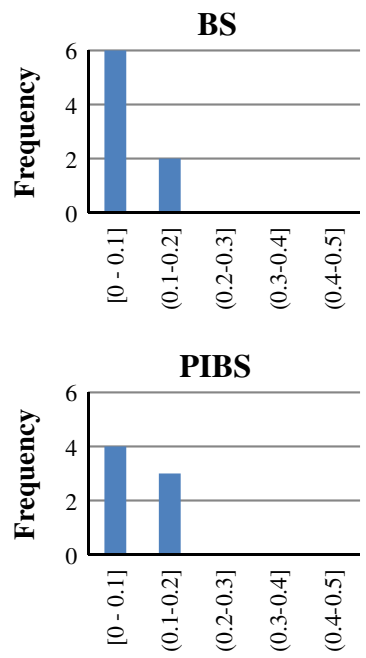
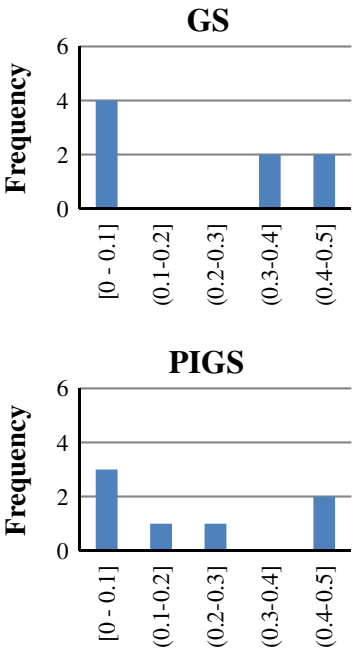

Fig. 2 Frequencies of return rates from singled out subjects

Result 3 Most preferred singled out matches, i.e. singled out subjects under a positive frame, behave bimodally, with either high or low return rates.

Result 3 implies that the variance of return rates of most preferred matches should be higher than that of return rates of baseline subjects; Siegel-Tukey tests support this $(p=0.007) .{ }^{26}$ Conversely, return rates variance by least preferred matches (BS and PIBS $)$ is not statistically different from that in the B treatment $(p=0.271),{ }^{27}$ and equally the variance of return rates by most preferred subjects in the B treatment does not differ from that of other baseline subjects $(p=0.164)$.

Going back to the regressions of Table 5, Authority $\times$ SDS17 is statistically significant $(p<0.05)$. This implies that authorities with a high score in the SDS17 questionnaire return proportionally more; this suggests that they perceive that social pressure is put on them (Zizzo and Fleming 2011).

The aggregate treatments dummy of regression 4 is mildly significantly negative $(p=0.052)$. In regression 3 , all the coefficients of treatment variables are negative.

\footnotetext{
26 A treatment-by-treatment comparison gives similar results (the $p$-values are 0.001 and 0.076 for respectively B versus GS and B versus PIGS).

27 A treatment-by-treatment comparison again gives similar results (the $p$-values are 0.561 and 0.611 for respectively B versus BS and B versus PIBS).
} 
However, only the coefficients of BS+PIBS and PG+PIGS are strongly and mildly statistically significant respectively. This evidence brings us to the next result that, relatively to trustworthiness, is strikingly in opposition to Conjecture 1 .

Result 4 There is some evidence that the presence of a singled out subject reduced return rates to non-singled out subjects. This is particularly prominent in the treatments where the singled out subject was the least preferred match.

Table 6 In the regressions on the giving rate to singled out subjects, all the coefficients of the treatments dummies are negative, but statistically not significant.

Result 5 Once covariates are controlled for, giving rates towards singled out subjects were not different from those towards baseline subjects.

Hence, although the sign of the coefficients in the regressions points to a negative effect, there is no statistical significant evidence that the singled out individual was trusted less than other individuals (i.e. Conjecture 1 does not hold with respect to trust).

Table 7 In the regressions on the return rate to singled out subjects, all the treatment dummies in regression 7 are negative, though only the coefficient on RS+ABS is statistically significant $(p<0.001)$. An $\mathrm{F}$ test restricting all the dummies corresponding to treatments where the singled out can be identified (BS, GS, RS, ABS) to 0 is rejected $(p<0.01)$. In addition, the Asterisk dummy of regression 7 is statistically significant $(p<0.01)$.

Result 6 Subjects who were not responsible of the distinct status of the singled out subject returned about $20 \%$ less to this person.

This result provides strong evidence in favor of Conjecture 3 with respect to trustworthiness.

In all the regressions, we control for demographic and psychological variables, and some of them turned out to be statistically significant. ${ }^{28}$

\section{Discussion}

Our experiment was the first to look at singling out in an economic setting and was run under a minimal and artificial manipulation. While obviously research with nat-

\footnotetext{
28 Most notably, participants with a background in economics gave less to both non-singled and singled out subjects; a similar behavioral pattern is observed for Muslim subjects and Indian subjects; while single participants gave and returned more to non-singled out subjects. Our psychological measures had limited power to explain trust game behavior. First, the risk attitude of the subjects, as measured in the Holt and Laury (2002) task, did not relate to trusting or trust fulfilling behavior, as already found in Tsutsui and Zizzo (forthcoming), Lönnqvist et al. (2010), and Houser et al. (2010). Second, although self-esteem is a key concept of social identity theory, our measure of self-esteem does not contribute to explain the behavior in our trust game. Third, other than in relation to authorities as just remarked on, the social desirability scale was unrelated to both trusting and trust fulfilling behavior. Since this measure is a proxy for experimenter demand effects (see Zizzo and Fleming 2011), the fact that it does not correlate with trust or trustworthiness in our experiment, and that our key results above are robust to controlling for it, inspires confidence for the robustness of our results to potential experimenter demand effects. In the on-line appendix, we also analyze the time trend of the key variables.
} 
ural group has merits, the artificial set-up is a good one to tackle a new area, reduces potential confounding such as natural group stereotyping and minimizes any potential experimenter demand effects. However, it is possible that stronger or less artificial manipulations (e.g., associating a status of being singled out with a specific socioeconomic characteristic) may provide additional insights in the understanding of how this social phenomenon works in the real world. Furthermore, we studied the implications of singling someone out in the specific setting of trust games. It is likely that singling someone out also affects the standard results of other experimental environments of interest to within-firm cooperation, such as public goods games, weakest link games and so on; it might also affect individual preferences for time or work productivity. This is why additional research should take place to confirm the robustness of our results and further our understanding of the implications of singling out.

One potential explanation of our findings might be that there is not a behavior change because of singling out. Rather, the singled out subjects may behave differently because individual characteristics information made them singled out (i.e., least preferred or most preferred) and implies that they behaved differently. The focus here is on individual characteristics information which was transmitted (e.g., age or PhD), and which may make the sample of singled out subjects different from the sample of non-singled out subjects. This individual characteristics hypothesis is within the realm of possibility in the least preferred and most preferred singled out subjects treatments precisely because the choice of such least preferred and most preferred singled out subjects may be non-random, as information is provided to subjects to choose their ranking of subjects they would wish to be matched with. ${ }^{29}$ We are able to control for this hypothesis in three complementary ways. First, in Sect. 3, we provided evidence on how the behavior of the least or most preferred matches in the B subjects, who were not singled out, was different from that of the least and most preferred matches in BS/PIBS and GS/PIGS treatments respectively, who were singled out. Specifically, the behavioral patterns identified by Results 2 and 3-such as the lower trustworthiness of singled out subjects-were not replicated by looking at least/most preferred matches in the B subjects. This implies that the act of singling out as opposed to the individual characteristics making a subject least or most preferred determined those results. Second, we control directly for various individual characteristics in the regression analysis presented in Tables 4 and 5, thus enabling us to identify the effects of singling out as separate to that of being a singled out subject. Third, and more fundamentally, the online appendix (section E) shows that the sample of singled out subjects does not differ from the sample of corresponding non-singled out subjects in almost all of the individual characteristics. As shown in the online appendix, $\mathrm{PhD}$ students were more likely to be least preferred, but the $\mathrm{PhD}$ dummy is statistically insignificant in

\footnotetext{
29 A reviewer suggested that non-singled out subjects might have formed correct beliefs about the trustworthiness of the singled out subject and this, in turn, explains trusters' propensity to trust. The only results we have in the paper regarding giving rates are Results 1 and 5, both of which are non-significance results. We cannot entirely rule out that, if this potential confound were taken into account, it would lead to greater significance of singling out for trust than we have found. The reason we did not elicit belief is because, in a first experiment, we wished to rule out the potential effect that eliciting belief may have had on later behavior (e.g., Croson 2000). However, we note that Results 2 and 4 imply that trusters with correct beliefs should have been less trusting of singled-out least preferred trustees, which is not what we find.
} 
all regressions in Tables 4, 5, 6 and 7, implying that it made no difference. ${ }^{30}$ Equally, UK subjects were more likely to be most preferred matches (see online appendix), but the UK dummy is again statistically insignificant in Tables 4, 5, 6 and 7, implying that they did not behave any differently from everyone else. Finally, single subjects were less likely to be most preferred matches, and what we find is that they were more trusting and trustworthy towards non-singled out subjects according to Tables 4 and 5. However, we have not found any evidence that high status subjects (i.e., the most preferred matches) are less trusting and trustworthy towards non-singled out subjects, and so this potential individual characteristic effect does not turn out to be relevant. It is, of course, anyway controlled for in the regression analysis.

As we can rule out the individual characteristics hypothesis as an explanation of our results, we conclude that singling out appears to matter as such. Insofar as we could glean from our experiment, we found no evidence suggesting that singling out is beneficial, at least with respect to trust or trustworthiness. We found it is irrelevant for trust and potentially disruptive for trustworthiness.

Trustworthiness of non-singled out subjects towards singled out subjects. In line with Conjecture 1, we found an overall reduction of trustworthiness of non-singled out subjects towards singled out subjects, and one largely focused on the RS and the ABS treatments. In these treatments, subjects returned around $20 \%$ less to the singled out subject compared to the baseline (Result 6), and over twice as large an effect relative to the other treatments. This effect holds even while controlling for covariates such as behavioral reciprocity (based on how much trustees were given by trusters) and any potential experimenter demand (as proxied by our social desirability scale measure). Our interpretation is that, in RS and ABS, the responsibility of choosing the singled out subject shifted to someone else, and, therefore, any concern for the singled out subject's condition was mitigated if not removed. Conversely, in the case of the other treatments, such concern could be present, as subjects may have felt responsible for the singled out subject, thus reducing the negative effect of perceiving the singled out individual as an outsider. This interpretation is in line with a responsibility-alleviation effect (Charness 2000) identified in Conjecture 3. A second explanation, which is still linked with a responsibility-alleviation argument, is that, in treatments such as BS, subjects might have thought to have made mistakes in the selection process of the singled out subject, and, therefore, did not want to take actions which could have harmed a "blameless" person. In other words, here the responsibility is not to have consciously singled someone out, but rather to have made mistakes in singling someone out. ${ }^{31}$

Trustworthiness of non-singled out subjects towards non-singled out subjects. ${ }^{32}$ In contrast to Conjecture 1, we found no evidence that singling out works as a bonding

\footnotetext{
30 Further evidence of the irrelevance of this variable for our findings on low status subjects (i.e. least preferred matches) is that the results of the regressions do not change if we drop the observations corresponding to $\mathrm{PhD}$ students selected as the least preferred match (3 observations).

31 Note that people might be in general more careful in evaluating top ranked choices than lower ranked choices (Hausman and Ruud 1987), and, therefore, commit increasing mistakes with the latter.

32 We obviously do not have a discussion of the trustworthiness of singled out subjects towards other singled out subjects since there was a single singled out subject in each session, and so no other singled out subject that each singled out subject could interact with.
} 
tool for other group members leading to greater in-group cooperation: relative to the baseline, there is no significant increase in trustworthiness from non-singled out subjects towards other non-singled out subjects. If anything, there is evidence the presence of a singled out subject reduced return rates to non-singled out subjects, notably (by around 10-11\%) in the treatments where the singled out subject was the least preferred match (Result 4 and Table 5). There are different possible reasons for this; we mention two. First, the presence of an a-prototypical member in the group may jeopardize the distinctiveness of the in-group as far as the singled out subject is not excluded from the group (Hogg et al. 2005). Second, non-singled out subjects may blame other non-singled out subjects for some responsibility for the singling out of a specific subject.

Trustworthiness of singled out subjects towards non-singled out subjects. It mattered for singled out subjects whether they were singled out for being the least preferred match or otherwise. In contrast to Conjecture 4 and in agreement with Conjecture 2, return rates by least preferred matches strikingly decreased from the $24 \%$ of the baseline to single digits (4-7\%) as per Table 3. According to the regressions in Table 5, once covariates are taken into account, subjects who were seen as least preferred matches were less trustworthy by as much as $16 \%$. It was not the act of being marked as low status that caused this reaction, since it occurred even in PIBS, when only least preferred matches knew they were the least preferred, and they knew that this was the case. We can also exclude the fact of being singled out as having such an effect per se, since we do not find the same large effect outside BS and PIBS. Rather, it was the fact of being considered by other subjects as undesirable that appears to have elicited the negative reaction. Many psychological studies show that people who have been excluded appear to engage in anti-social behaviors (e.g. Twenge et al. 2001). Our manipulation does not imply exclusion. Nevertheless, some of the underlying psychological forces motivating excluded people to engage in self-defeating social behaviors might also be the same that trigger the anti-social behavior of the singled out subject. Anger, resentment, and reciprocity might be the driving forces of such retaliatory behavior.

Most preferred singled out matches, i.e. singled out subjects under a positive frame, behaved bimodally, with either high or low return rates (Result 3 and Fig. 2). This result supports at the same time both Conjectures 2 and 4. One interpretation of this result is that it reflects some of the mixed results of the psychological research on leadership theory. Highly prototypical subjects should display more distinct group behaviors, and, therefore, more in-group favoritism (Hogg 2001). However, the status-based gap between the highly prototypical subject and the rest of the group may transform an intra-group relationship between the consensually liked subject and the others into an inter-group relationship (Hogg 2001). Due to this, the singled out subject may behave in a more anti-social way toward the lower status subjects. Our results suggest that both behavioral patterns may describe the singled out subject's decision whether to fulfill trust. Which behavior turns out to happen probably depends on whether the most preferred singled out individual perceives himself or herself as an insider or outsider.

Another interpretation of our bimodality finding is that it may also be explained by the particular beliefs of most preferred matches, quite independently of group identity concerns. The most preferred singled out subject might have believed to be selected by others because of strategic reasons rather than niceness (i.e. he or she was 
considered the most exploitable subject in the groups), and, therefore, he or she might have behaved antisocially in response to such attribution (in the spirit of McCabe et al. 2003). Alternatively, the fact that he or she is considered most preferred might support a belief that trust is being placed on him or her, and that he or she should feel let down if trust is not fulfilled; this would lead to more pro-social behavior (e.g., Dufwenberg and Gneezy 2000; Battigalli and Dufwenberg 2007). Our design does not allow us to disentangle these alternative explanations, and it would therefore be worthwhile to investigate this in further research.

Trustworthiness of authorities towards non-singled out subjects. ${ }^{33}$ ABS treatment authorities had a return rate of just around 7-8\%. The reduction in trustworthiness is moderated by experimenter and social demand: subjects more sensitive to social pressure such as experimenter demand return comparatively more, as shown by the significance of SDS17 $\times$ Authority in the Table 5 regressions. Nevertheless, Table 5 also shows that the effect persists when controlling for our social desirability scale measure that we employ to control for experimenter demand.

We should point out that the aim of our experiment was not to study the behavior of the authority. We simply wanted to investigate the effects of singling out when a specific individual rather than the entire group is responsible for the lower-status attribution. Different conjectures might explain why the authority did not fulfill trust. We mention two. First, authorities might have felt that, since their co-participants had been assessed as comparatively worthy matches, they should be more generous in their giving. Second, they may have felt entitled to keep more money because he or she had already a service to everyone else by helping identify the least preferred match.

Our starting point was the fact that singling out is a pervasive phenomenon of economic and social life. We found that singling out individuals does not carry any benefit in terms of trust and has a negative effect for trustworthiness. Obviously, further research is needed and singling out may yet have benefits for organizations-if, for example, it is connected to social rewards and therefore can be used to elicit greater work productivity. However, if you are a manager and you are considering singling out someone for blame and praise, you may wish to bear in mind that this, and especially the former, may disrupt the social glue holding the team together.

Acknowledgments We wish to thank seminar participants at the University of East Anglia, at CREED in Amsterdam, at the ASFEE conference in Montpellier, at the ICCSR Workshop in Nottingham, and at the Young Economists' Workshop in Forlì, Davide Dragone, Anders Poulsen, Abhijit Ramalingam, Robert Sugden, Marie Claire Villeval, Luca Zarri, the editors and two reviewers for useful feedback and advice, and the University of East Anglia for financial support.

Open Access This article is distributed under the terms of the Creative Commons Attribution License which permits any use, distribution, and reproduction in any medium, provided the original author(s) and the source are credited.

\footnotetext{
33 We do not discuss the trustworthiness of authorities towards singled out subjects since, as noted earlier, authorities were not matched with singled out subjects. Also, non-singled out subjects did not know they were matched with an authority, and so could not condition their behavior on a subject being marked as an authority.
} 


\section{References}

Abrams D, Hogg MA, Marques JM (eds) (2005) The social psychology of inclusion and exclusion. Psychology Press, New York

Arbak E, Villeval M (2013) Voluntary leadership: motivation and influence. Soc Choice Welf 40(3):635-662

Arrow K (1974) The limits of organizations. Norton, New York

Ball SB, Eckel C (1998) The economic value of status. J Socio-Econ 27:495-514

Ball SB, Eckel C, Grossman PJ, Zame W (2001) Status in markets. Q J Econ 116(1):161-188

Battigalli P, Dufwenberg M (2007) Guilt in games. Am Econ Rev Pap Proc 97(2):170-176

Berg J, Dickhaut J, McCabe K (1995) Trust, reciprocity, and social-history. Games Econ Behav 10(1):122142

Brandts J, Cooper D, Weber R (2011) Legitimacy, social distance, and leadership in the turnaround game. Florida State University Working Paper

Buchan NR, Johnson EJ, Croson RTA (2006) Let's get personal: an international examination of the influence of communication, culture and social distance on other regarding preferences. J Econ Behav Organ 60(3):373-398

Chakravarty S, Fonseca, MA (2012) The effect of social fragmentation on public good provision: an experimental study. Discussion Paper 1207, Exeter University

Charness G (2000) Responsibility and effort in an experimental labor market. J Econ Behav Organ 42(3):375-384

Charness G, Rabin M (2002) Understanding social preferences with simple tests. Q J Econ 117(3):817-869

Charness G, Haruvy E, Sonsino D (2007) Social distance and reciprocity: an internet experiment. J Econ Behav Organ 63(1):88-103

Charness G, Masclet D, Villeval M (2013) The dark side of competition for status. Manag Sci 60(1):38-55

Chen Y, Li SX (2009) Group identity and social preferences. Am Econ Rev 99(1):431-457

Chen R, Chen Y (2011) The potential of social identity for equilibrium selection. Am Econ Rev 101(6):25622589

Croson R (2000) Thinking like a game theorist: factors affecting the frequency of equilibrium play. J Econ Behav Organ 41(3):299-314

DePaulo BM, Morris WL (2006) The unrecognized stereotyping and discrimination against singles. Curr Dir Psychol Sci 15(5):251-254

Derfler-Rozin R, Pillutla M, Thau S (2010) Social reconnection revisited: the effects of social exclusion risk on reciprocity, trust, and general risk-taking. Organ Behav Hum Decis Process 112(2):140-150

Dufwenberg M, Gneezy U (2000) Measuring beliefs in an experimental lost wallet game. Games Econ Behav 30(2):163-182

Eckel CC, Fatas E, Wilson R (2010) Status and cooperation in organizations. J Public Econ Theory 12(4):737-762

Eriksson T, Mao L, Villeval M (2012) Losing Face. Mimeo

Falk A, Fischbacher U (2006) A theory of reciprocity. Games Econ Behav 54(2):293-315

Fehr E, Schmidt KM (1999) A theory of fairness, competition, and cooperation. Q J Econ 114(3):817-868

Fischbacher U (2007) Z-Tree: Zurich Toolbox for ready-made economic experiments. Exp Econ 10(2):171178

Frank RH (1988) Passions within reason: the strategic role of emotions. Norton, New York

Gächter S, Nosenzo D, Renner E, Sefton M (2012) Who makes a good leader? Cooperativeness, optimism, and leading-by-example. Econ Inq 50(4):1465-7295

Greiner B (2004) The online recruitment system ORSEE 2.0 - a guide for the organization of experiments in economics. University of Cologne, Working Paper Series in Economics 10(23), pp 63-104

Guerra G, Zizzo DJ (2004) Trust responsiveness and beliefs. J Econ Behav Organ 55(1):25-30

Güth W, Levati MV, Sutter M, van der Heijden E (2007) Leading by example with and without exclusion power in voluntary contribution experiments. J Public Econ 91(5-6):1023-1042

Hargreaves-Heap SPH, Varoufakis Y (2002) Some experimental evidence on the evolution of discrimination, co-operation and perceptions of fairness. Econ J 112(481):679-703

Hargreaves-Heap SPH, Zizzo DJ (2009) The value of groups. Am Econ Rev 99(1):295-323

Hausman JA, Ruud PA (1987) Specifying and testing econometric-models for rank-ordered data. J Econom 34(1-2):83-104

Heatherton TF, Hebl MR, Hull JG, Kleck RE (eds) (2000) The social psychology of stigma. Guilford Press, New York, NY 
Heikes EJ (1991) When men are the minority—the case of men in nursing. Sociol Q 32(3):389-401

Hogg MA (2001) A social identity theory of leadership. Pers Soc Psychol Rev 5(3):184-200

Hogg MA, Fielding KS, Darley J (2005) Fringe dwellers: processes of deviance and marginalization. In: Abrams D, Hogg MA, Marques JM (eds) The social psychology of inclusion and exclusion. Psychology Press, New York, pp 191-210

Holt CA, Laury SK (2002) Risk aversion and incentive effects. Am Econ Rev 92(5):1644-1655

Houser D, Schunk D, Winter J (2010) Distinguishing trust from risk: an anatomy of the investment game. J Econ Behav Organ 74(1-2):72-81

Kanter RM (1977) Some effects of proportions on group life-skewed sex-ratios and responses to token women. Am J Sociol 82(5):965-990

Korsgaard MA, Schweiger DM, Sapienza HJ (1995) Building commitment, attachment, and trust in strategic decision-making teams - the role of procedural justice. Acad Manag J 38(1):60-84

Lönnqvist J, Verkasalo M, Walkowitz G, Wichardt PC (2010) Measuring individual risk attitudes in the lab: task or ask? An empirical comparison. Working Paper SSRN eLibrary

Marquardt DW (1980) A critique of some ridge-regression methods-comment. J Am Stat Assoc 75(369):87-91

McCabe KA, Rigdon ML, Smith VL (2003) Positive reciprocity and intentions in trust games. J Econ Behav Organ 52(2):267-275

Neckermann S, Cueni R, Frey BS (2012) Awards at work. Working Paper SSRN eLibrary

Niemann YF, Dovidio JF (1998) Relationship of solo status, academic rank and perceived distinctiveness to job satisfaction of racial/ethnic minorities. J Appl Psychol 83(1):55-71

Pan XS, Houser D (2011) Competition for trophies triggers male generosity. PLoS ONE 6(4):e18050

Pickett CL, Brewer MB (2005) The role of exclusion in maintaining ingroup inclusion. In: Abrams D, Hogg MA, Marques JM (eds) The social psychology of inclusion and exclusion. Psychology Press, New York, pp 89-111

Potters J, Sefton M, Vesterlund L (2007) Leading-by-example and signaling in voluntary contribution games: an experimental study. Econ Theory 33(1):169-182

Putnam RD (2000) Bowling alone: the collapse and revival of american community. Simon \& Schuster, New York

Rivas MF, Sutter M (2011) The benefits of voluntary leadership in experimental public goods games. Econ Lett 112(2):176-178

Rosenberg M (1965) Society and the adolescent self-image. Princeton University Press, Princeton

Sekaquaptewa D, Thompson M (2002) The differential effects of solo status on members of high- and low-status groups. Pers Soc Psychol Rev 28(5):694-707

Smith KG, Carroll SJ, Ashford SJ (1995) Intraorganizational and interorganizational cooperation-toward a research agenda. Acad Manag J 38(1):7-23

Stöber J (2001) The social desirability scale-17 (Sds-17) — convergent validity, discriminant validity, and relationship with age. Eur J Psychol Assess 17(3):222-232

Tajfel H, Turner J (1979) An integrative theory of intergroup conflict. In: Austin W, Worchel S (eds) The social psychology of intergroup relations. Brooks Cole, Monterey, pp 33-47

Tan JHW, Bolle F (2007) Team competition and the public goods game. Econ Lett 96(1):133-139

Thau S, Aquino K, Poortvliet PM (2007) Self-defeating behaviors in organizations: the relationship between thwarted belonging and interpersonal work behaviors. J Appl Psychol 92(3):840-847

Tsutsui K, Zizzo DJ (2013) Group status, minorities and trust. Exp Econ. doi:10.1007/s10683-013-9364-x

Twenge JM, Baumeister RF, Tice DM, Stucke TS (2001) If you can't join them, beat them: effects of social exclusion on aggressive behavior. J Pers Soc Psychol 81(6):1058-1069

Twenge JM, Baumeister RF, DeWall CN, Ciarocco NJ, Bartels JM (2007) Social exclusion decreases prosocial behavior. J Pers Soc Psychol 92(1):56-66

Yoder J, Aniakudo P (1997) "Outsider within" the firehouse-subordination and difference in the social interactions of african american women firefighters. Gender Soc 11(3):324-341

Zizzo DJ, Fleming P (2011) Can experimental measures of sensitivity to social pressure predict public good contribution? Econ Lett 111(3):239-242 